Revista Kinesis, Santa Maria v.35 n.2, 2017, maio - ago. , p. 75- 83 Centro de Educação Física e Desporto - UFSM

\title{
A EDUCAÇÃO FÍSICA COMO POSSIBILIDADE DE ANÁLISE DE DOCUMENTOS MÉDICOS DO BRASIL DO FINAL DO SÉCULO XIX
}

\author{
PHYSICAL EDUCATION AS POSSIBILITY OF ANALYSIS OF MEDICAL RECORDS OF THE LATE NINE- \\ TEENTH-CENTURY BRAZIL \\ LA EDUCACIÓN FÍSICA COMO POSIBILIDAD DE ANÁLISIS DE REGISTROS MÉDICOS DE FINALES \\ DEL SIGLO XIX BRASIL
}

\author{
Felipe Lameu dos Santos \\ Universidade Federal Rural do Rio de Janeiro \\ felipelameu@gmail.com
}

\section{Resumo}

Neste artigo defendo a hipótese de que a educação física entendida como uma expressão de época é a forma mais adequada para tratar a documentação médica sobre educação física no Brasil dos anos finais do século XIX. Defendo que essa perspectiva só é possível a partir do trabalho empírico com a documentação histórica e no diálogo constante entre as perguntas formuladas no presente com os vestígios históricos representados pela documentação.

Palavras-Chave: Educação física. História. Historiografia.

\section{ABSTRACT}

In this paper I argue the hypothesis that physical education understood as an expression of epoch is the most appropriate way to treat medical documentation on physical education in Brazil in the final years of the nineteenth century. I argue that this perspective is only possible from the empirical work with the historical documentation and the constant dialogue between the questions raised in the present with historical vestiges represented by documentation.

Keywords: Physical education. History. Historiography.

\section{RESUMEN}

En este articulo sostengo la hipótesis de que la educación física entendida como una expresión del tiempo es la forma más adecuada para el tratamiento de la documentación médica sobre la educación física en Brasil en los últimos años del siglo XIX. Insistimos en que este punto de vista sólo es posible desde el trabajo empírico con la documentación histórica y el diálogo constante entre las cuestiones planteadas en el presente con los restos históricos representados por la documentación. 


\section{Introdução}

\section{Questões sobre a historiografia da educação física}

Este texto é fruto de algumas reflexões ocorridas durante a escrita de uma dissertação de mestrado que tinha como objetivo realizar uma história do que era entendido como educação física e as relações com as propostas de formas de higienizar a população brasileira segundo parte da medicina entre os anos de 1870 e 1892. Os principais documentos utilizados para realizar tal pesquisa foram as teses da Faculdade de Medicina do Rio de Janeiro, artigos de dois periódicos médicos e as conferências populares da Glória entre 1870 e 1892. Durante a leitura da documentação e escrita da dissertação algumas questões metodológicas foram enfrentadas no que diz respeito ao entendimento do que era educação física na documentação pesquisada. É sobre essas questões metodológicas que trata este artigo.

Um olhar sobre a produção historiográfica da área da educação física sobre o período do século XIX demonstra que o termo educação física não se limitava a algo necessariamente ligado ao exercício físico ou a uma disciplina escolar. No século XIX, faziam parte da educação física uma ampla gama de aspectos como: a ginástica, a arquitetura dos edifícios, a alimentação, o banho, o asseio, a dança, o canto, a declamação, a natação, a esgrima, os jogos, o sport, a equitação, os passeios e a caça. Tudo que dizia respeito ao desenvolvimento físico podia ser enquadrado de alguma forma na educação física. Contudo, tem sido tendência na historiografia da Educação Física sobre o século XIX a formulação de problemas com ênfase em objetos relacionados ao exercício físico ou a algo relacionado a uma disciplina escolar. Neste texto defendo outra perspectiva. Proponho que para tratar a documentação médica sobre educação física no final do século XIX devemos compreender a educação física dentro de sua amplitude, ou seja, fazer uma história do que era entendido por educação física na época dentro de seu contexto social e cultural.

O termo "educação física" utilizado no Brasil do século XIX diferencia-se bastante do entendimento da Educação Física como área de estudos e disciplina escolar intimamente relacionada ao corpo em movimento como hodiernamente entende-se. Isso implica desafios, dificuldades e possibilidades metodológicas para o estudo histórico da Educação Física. Duas entradas possíveis serão tratadas nesse texto: (1) a possibilidade de estudo da história da Educação Física no século XIX por meio da história da educação do corpo; (2) a utilização, no trato das fontes, do termo "educação física" tal qual designavam os autores da documentação, a "educação física" como uma expressão de época.

Sem a pretensão de esgotar o debate sobre as possibilidades metodológicas dos termos "educação física" e "educação do corpo" para o estudo da História da Educação Física no Brasil nos anos finais do século XIX, mas simplesmente socializar os subsídios utilizados na construção de uma dissertação de mestrado, trabalharei com a hipótese de que o termo "educação física" é o mais adequado para o trato médicas sobre educação física no final do século XIX. Para defender essa posição realizarei um debate historiográfico atento ao uso do termo "educação física", das fontes e dos problemas de pesquisa de parte da produção historiográfica da Educação Física desde a década de 1980 até estudos mais recentes.

\section{Década de 1980: a historiografia da "crise" na educação física}

Durante a década de 1980 muitos trabalhos importantes para a área da Educação Física foram gestados e publicados. Na História da Educação Física brasileira, dentre as publicações mais importantes pode-se incluir os livros Educação Física no Brasil: a história que não se conta, de Lino Castellani Filho (CASTELLANI FILHO, 1988); Educação Física Progressista: a pedagogia crítico-social dos conteúdos, de Paulo Ghiraldelli Junior (GHIRALDELLI JUNIOR, 1989) ; Educação Física: raízes européias e Brasil, de Carmen Lúcia Soares (SOARES, 2004 [1994]). Esses trabalhos foram desenvolvidos no momento que estes 
autores eram discentes do Programa de Pós-graduação na área de Educação da PUC-SP, um espaço de efervescência do pensamento crítico na Educação naquele momento . Não por acaso, esses textos foram de grande importância para o debate da Área da Educação Física que também vivia uma efervescência de pensamento crítico (MELO, 1995, p. 136).

Em maior ou menor grau, os trabalhos da historiografia da Educação Física daquele período buscavam reescrever a História da Educação Física a partir de um viés crítico. O principal alvo das críticas eram os trabalhos de Inezil Penna Marinho que, segundo Castellani, homogeneizavam o conhecimento da área (CASTELLANI FILHO, 1988, p. 15).

Sobre o século XIX, Soares, Castellani Filho e Ghiraldelli Junior concordavam com a proposição de que a educação física no Brasil era devedora dos saberes vindos dos meios militares e da medicina. Os três autores seguiam com o argumento de que a educação física do período final do dezenove era pensada como uma forma de melhorar o estado de saúde do brasileiro. Para Castellani Filho, os médicos se preocuparam em denunciar os malefícios das formas e estruturas coloniais de se lidar com o corpo, e, se autoproclamaram como os mais competentes para redefinir os padrões de conduta física, moral e intelectual dos brasileiros, calcados numa medicina de cunho higienista. Segundo ele, nesse projeto dos médicos, a educação física seria uma forma de redefinição do corpo do brasileiro agindo nos aspectos físicos e morais. Já para Ghiraldelli Junior, a educação física tinha como objetivo disciplinar os hábitos para que as pessoas se afastassem de práticas capazes de provocar a deterioração da saúde e da moral.

Soares também concordava com essas proposições. Todavia, sua análise foi mais detalhada e profunda. Um ponto muito importante em seu trabalho foi a distinção entre "Educação Física" e "educação física". A primeira como um componente da educação formal ligada à prática de atividades físicas, a segunda como algo mais amplo não necessariamente ligado ao corpo em movimento. Dos autores da década de 1980, Soares foi a única que atentou para o fato de que a educação física não representava necessariamente algo relacionado ao corpo em movimento no século XIX. Talvez, isso se devesse a questões metodológicas do trabalho de Soares. Essa autora foi a única a utilizar fontes documentais, tendo contato com textos produzidos no século XIX e podendo perceber que a educação física possuía um conceito muito mais amplo naquele período. Contudo, na pesquisa de Soares, o foco estava no que ela designou por "Educação Física”.

Como as perguntas nascem no presente e o passado é uma construção do presente (KNAUSS, 2009, p.10) se os pesquisadores da História da Educação Física não manusearem os documentos perguntas só poderão questionar sobre o que se entende por educação física no momento em que suas perguntas são realizadas. Apesar do enfoque dado por Soares ter recaído sobre a "Educação Física", seu contato com a documentação já dava indícios de novas perguntas que poderiam ser feitas a partir dos documentos que mobilizou. Outra educação física no século XIX ainda estava por ser compreendida, uma educação física ampla.

As fontes documentais utilizadas por Carmen Lúcia Soares para o século XIX foram o Decreto n. 7.247 de 19 de Abril de 1879 (Reforma Leôncio de Carvalho) e o Parecer de Rui Barbosa. Ghiraldelli Junior e Castellani Filho utilizavam um número bem reduzido de fontes documentais. Ghiraldelli Junior, por exemplo, não utilizava nenhuma fonte além do Parecer de Rui Barbosa para tratar do século XIX, e mesmo essa fonte ele utilizou segunda mão, a partir de um texto de Lourenço Filho: A pedagogia de Rui Barbosa. Castellani Filho também não utilizava nenhuma fonte documental para o século XIX, ele fez menção apenas ao Parecer de Rui Barbosa, citado a partir do livro História Geral da Educação Física, de Inezil Penna Marinho. Outras fontes vieram dos trabalhos de Jurandir Freire Costa, Ordem médica e norma familiar; e Francisco Alencar, História da sociedade brasileira. Os problemas metodológicos relacionados ao baixo número de fontes foi questão de debates e críticas na História de Educação Física durante o período da década de 1990. 


\section{A década de 1990: a crítica sobre a crítica}

A década de 1990 foi de grande importância para consolidação da área de estudos sobre História da Educação Física no contexto brasileiro. Observar-se uma série de iniciativas que tentavam congregar os novos pesquisadores dessa Área que estavam se formando nos cursos de pós-graduação em Educação Física, Educação e História ; foram criadas as primeiras linhas de pesquisa ligadas à História da Educação Física em programas Stricto Sensu em Educação Física e surgiu o primeiro grupo de pesquisa cadastrado no CNPq sobre o tema (MELO, 1996, p. 41). Os pesquisadores em História da Educação Física começaram a se organizar no maior espaço de debate da Educação Física no Brasil, o Colégio Brasileiro de Ciências do Esporte (SOARES, 2003a). Surgiram os Encontros Nacionais de Historia da Educação Física e do Esporte e foi produzida a coleção Pesquisa história na Educação Física, organizada por Amarílio Ferreira Neto, da Universidade Federal do Espírito Santo.

Também, nessa década, começaram as críticas à historiografia produzida durante a década de 1980 e observou-se uma maior aproximação por parte dos pesquisadores da História da Educação Física das metodologias da área de História. Discussões sobre as fontes utilizadas foram travadas e surgiu uma maior diversidade dos objetos de pesquisa .

Dentro deste panorama, em que a História da Educação Física buscava novos documentos, reler abordagens metodológicas, rever antigos objetos utilizando fontes mais usuais ou inventando novas formas de reconstruir os indícios, é que pretendo fazer um panorama do que foi produzido sobre a educação física e sua relação com a medicina no século XIX caminhado em direção a discussão sobre o uso do termo educação física no trato das fontes. Dialogarei com alguns estudos publicados pela Coleção Pesquisa Histórica na Educação Física. Optei por analisar os trabalhos relacionados à medicina e à educação física no século XIX. Foquei nos argumentos principais dos textos e nas fontes utilizadas.

Pedro Angelo Pagni (PAGNI, 1997) tinha como objetivo analisar como a educação física e o esporte fizeram parte dos hábitos e cuidados com o corpo entre os anos 1850 até 1920, bem como, as dificuldades de difusão dessas atividades. Ele utilizava como fontes para tratar do século XIX as teses médicas e os manuais pedagógicos. Contudo ele não especificou quais eram essas teses e esses manuais, prejudicando a crítica de sua análise.

Segundo seu trabalho, os exercícios físicos foram indicados nos manuais e nas teses médicas num processo de disseminação de hábitos higiênicos que visavam normatizar as famílias e influir na educação das futuras gerações. Segundo ele, a principal função dos exercícios indicados era disciplinar e moralizar a população. Dentre os exercícios físicos indicados podia-se encontrar a ginástica, a caminhada e, por vezes, a natação.

A partir do Ateneu, de Raul Pompeia (POMPEIA, 2009), Pagni demonstrava que nem sempre os exercícios indicados nas teses e nos manuais eram utilizados pelos alunos com os objetivos propostos pelos professores e diretores. Por vezes, esses exercícios eram um meio de burlar as rígidas regras de disciplina imposta aos alunos e uma oportunidade de sair dos muros das escolas (PAGNI, 1997, p. 61-3). Essa consideração de Pagni é um indício de um novo olhar que começava a ser construído na historiografia da Educação Física. Nos estudos da década de 1980, os autores estavam mais preocupados sobre o que se pensou sobre a educação física. Na década de 1990, começou-se a dar alguma atenção para os embates entre o que os médicos e diretores pretendiam com as práticas de exercício físico e como essas práticas eram apropriadas por seus praticantes.

Em Pagni observa-se a busca nas fontes de uma disciplina escolar, a Educação Física, que em muitos momentos confundi-se com a ginástica. Nesse trabalho, a busca ainda era de uma disciplina escolar ligada ao exercício físico. Outro era o sentido no trabalho de Vago (VAGO, 1997), que estava tentando entender o processo de escolarização da "Ginástica" nas escolas normais de Minas Gerais nos anos finais do século XIX e começo do XX. Entretanto, a partir de suas fontes ele percebeu que a educação física não 
era entendida, então, como um componente curricular específico ou como uma disciplina escolar.

Vago apresentou uma educação física ligada à tríade da educação intelectual, moral e física, em que a educação física estava mais ligada ao aprimoramento do aspecto físico da educação, mas não deixava de ser importante nos preceitos morais e intelectuais. Apenas a partir de 1890, segundo Vago, apareceu a especialização de um componente curricular chamado "Ginástica" dentro da educação física nas escolas normais (VAGO, 1997, p. 34-5).

A partir das fontes o objeto de pesquisa de Vago transformou-se. Passou da "Ginástica" para a "educação física" na forma mais ampla como se indicava em suas fontes, processo semelhante ao que aconteceu parcialmente em Soares (SOARES, 2004). Isso demonstra como o contanto com as fontes começou a mudar a forma de se fazer História da Educação Física: novos problemas começaram a surgir e novas formas de entender o que era "educação física" ao longo do tempo. Outro aspecto marcante no trabalho de Vago foi o maior número de fontes quando comparado aos trabalhos anteriormente analisados.

A questão das fontes foi um importante tema de debate na historiografia da Educação Física na década em 1990. Pode-se citar, por exemplo, a recorrência a crítica ao baixo número de fontes documentais nos trabalhos da área (MELO et al., 1998; MELO, 1999; CUNHA JUNIOR, 1998) e o desenvolvimento de um volume da coleção Pesquisa História na Educação Física que privilegiou essa discussão (FERREIRA NETO, 1998).

Em 1998, Carlos Fernando Cunha Junior (1998) publicou um levantamento realizado na Biblioteca Nacional do Rio de Janeiro sobre documentos publicados em língua portuguesa relacionados à Educação Física e à ginástica no século XIX. Nesse levantamento foi totalizado um total de dezoito documentos: três eram teses médicas, nove livros-manuais de Educação Física/ginástica e um manual que não era apenas sobre Educação Física, entretanto, possuía grande parte dedicada a ela (CUNHA JUNIOR, 1998, p 21-5).

Além de buscar esses documentos, Cunha Junior os transformou em fontes . Sua principal questão era descobrir quem produziu os manuais e livros destinados à educação física, chegando à conclusão de que esses manuais eram produzidos por médicos e ex-alunos dos cursos de ginástica e que havia uma circularidade de conhecimentos entre esses dois grupos (CUNHA JUNIOR, 1998, p. 25-8).

Um ponto interessante no trabalho de Cunha Junior era a busca de um enfoque menos "sintético" e "genérico" como, usualmente, podia-se encontrar nos trabalhos da historiografia da Educação Física da década de 1980 (CUNHA JUNIOR, 1998, p. 22). Essa busca de conclusões menos generalizantes era uma novidade na História da Educação Física e o trabalho de Cunha Junior é um exemplo importante desse movimento.

Paralelamente a esses autores, Victor Andrade de Melo (1998) apontava que a ginástica não era o único conteúdo nas aulas de educação física no século XIX. Segundo sua pesquisa, o esporte dividia espaço com a ginástica entre os conteúdos das aulas de Educação Física. Para chegar a essa conclusão, Melo utilizou uma fonte pouco comum na historiografia da Educação Física naquele momento: o Jornal do Comercio. Além desse jornal, encontrava-se entre suas fontes a legislação e o Parecer de Rui Barbosa.

Seu trabalho apresentava conclusões muito originais para o período. Ele percebeu que, embora a legislação determinasse a ginástica como conteúdo das práticas de exercícios físicos escolarizados e houvesse uma maior valorização da ginástica de forma geral, podia-se observar que, principalmente nas escolas com influência européia, o esporte tinha grande penetração e que, por vezes, a ginástica e o esporte conviviam como conteúdos possíveis (MELO, 1998, p. 60-1). Com isso poder-se-ia supor que nem sempre o que estava escrito nos documentos oficiais era respeitado no cotidiano das escolas. Essa conclusão vai ao encontro do texto de Pagni (1997) que também percebeu que nem sempre o escrito era respeitado. As conclusões de Melo e Pagni abriam novas possibilidades para a História da Educação Física, outras histórias poderiam ser contadas. 
Grande parte das pesquisas de 1990 já percebia que no século XIX a educação física não era utilizada para designar uma disciplina escolar. Entretanto, o enfoque dessas pesquisas estava na busca de um componente curricular ligado ao exercício físico na escola ou algo parecido. Como já foi apontado, Vago (1997) caminhava num outro sentindo, mas foi no texto fruto de algumas reflexões da tese de doutoramento de Carmen Lúcia Soares (1996) que essa questão ganhou destaque.

O objetivo do texto Imagens do corpo "educado: um olhar sobre a ginástica no século XIX (SOARES, 1997) publicado na coleção História da Educação Física era entender como se deu o projeto de "educação corporal" na sociedade ocidental moderna, principalmente a partir do século XIX, lançando foco na ginástica de Amoros (SOARES, 1997, p. 5). Para isso, Soares utilizava como principal fonte o Nouveau Manuel d'education physique, gymnastique et morale de 1838. Mas, a ênfase maior do trabalho deu-se no diálogo com autores que tratam o corpo no século XIX como: Vigarello, Revel, Vovelle, Foucault e Bakthin.

Nesse texto, a educação do corpo ganha grande espaço em suas reflexões. Talvez, o "corpo" seja tematizado para resolver a questão da distinção entre "Educação Física" e "educação física" que aparecia no livro fruto de sua dissertação de mestrado (SOARES, 2004). De uma forma diferente da que fez em Educação Física: raízes européias e Brasil, a partir de sua tese, muito influenciada por Foucault e Vigarello, Soares deu mais ênfase ao segundo termo "educação física" correlacionando-o à "educação do corpo" como "pedagogia do gesto e da vontade"

\section{Possibilidades de análise em breve diálogo com a historiografia recente: educação física ou educação do corpo?}

Em prefácio de livro sobre o tema da educação do corpo na escola (OLIVEIRA, 2006), Carmen Lúcia Soares defendeu a "educação do corpo na escola" como objeto possível para a História da Educação e História da Educação Física (SOARES, 2006, p. x). Ela afirmava que o estudo da educação do corpo na escola é intermediado por uma gama de saberes e práticas que vão da higiene às boas maneiras, dos usos da água como forma de prazeres específicos ou como forma de limpeza, dos modos de alimentar-se, vestir-se, amar, dos modos de adoecer, de curar-se, de se exercitar, de nascer e morrer (SOARES, 2006, p. xiii).

Ao analisar a documentação médica do século XIX sobre educação física durante o trabalho de pesquisa para escrita da dissertação em conjunto com a produção da historiografia da Educação Física percebi que a educação física nos anos finais do século XIX era entendida de forma ampla e que abarcava os aspectos que Soares apontava como "intermediadores" da educação do corpo. Isso, inicialmente, poderia fazer crer que a "educação do corpo" seria o melhor caminho para balizar uma análise sobre a educação física na documentação médica do final do século XIX. Todavia E. P. Thompson (1998a, p. 63; 1998b, p. 102) alerta que o historiador deve realizar sua pesquisa com uma concepção, simultaneamente, fertilizada por conceitos sociológicos e arredia diante de categorias sociológicas. A teoria sociológica não pode prevalecer sobre o fenômeno histórico que propomos analisar. Com isso, veio a seguinte questão: ao utilizar a "educação do corpo" como chave para a análise, não se estaria impondo uma categoria forjada no presente sobre o fenômeno histórico analisado? Afinal, se fontes demonstram que o sentido amplo da "educação física" daria conta de sustentar a análise do que os médicos englobavam nos cuidados com os corpos. Mais adequado não seria usar o próprio conceito que eles utilizavam? O mais adequado não seria pensar a "educação física" como uma expressão de época dentro do seu contexto social e cultural? Para resolver esse impasse vamos voltar nossa atenção para textos recentes que tratassem da relação entre a medicina e a Educação Física no século XIX para perceber como a "educação física" tem sido percebida.

Edivaldo Góis Junior (GÓIS JUNIOR, 2013) pretendeu compreender a "mentalidade" médica sobre a "Ginástica" como prática corporal escolarizada no contexto do Brasil do século XIX e início do século XX, utilizando como fontes as teses da Faculdade de Medicina do Rio de Janeiro e da Faculdade de 
Medicina da Bahia, documentos da Academia Imperial de Medicina e da Escola Normal de São Paulo.

Em seu trabalho, percebe-se uma crítica às explicações "estruturantes" sobre a "Ginástica" presentes na historiografia da Educação Física da década de 1980. A preocupação com a "Ginástica" na escola demonstrava que esse autor estava focando seu estudo em uma prática de exercício escolarizado, mesmo percebendo que a "educação física" era entendida naquele momento de forma muito mais ampla do que era a "Ginástica" (GOís JUNIOR, 2013, p. 147).

Nesse trabalho, em certos momentos, ocorreu o uso indiscriminado do termo educação física. Por vezes, ele era utilizado para designar a "Ginástica", outras vezes uma disciplina escolar e, ainda, a educação física de forma ampla. O termo educação física às vezes aparece com letras maiúsculas (GÓIS JUNIOR, 2013, p. 149) e outras com letras minúsculas (GÓIS JUNIOR, 2013, p. 154).

O tema central do texto de Góis Junior era a "Ginástica". A "Ginástica" como objeto no trabalho de Góis Junior parece estar relacionada à busca constante na historiografia da Educação Física de atentar para objetos que de alguma forma lembrem uma prática de exercício físico no ambiente escolar. Pois ele reconhece a amplitude do termo, mas opta por abordar algo relacionado ao corpo em movimento ou algo próximo a uma disciplina escolar.

Um texto que contava com Góis Junior e mais dois de seus orientandos (COSTA, SANTOS e GÓIS JUNIOR, 2014) tinha o objetivo de descrever o contexto de escolarização da Educação Física no século XIX mediante o discurso médico. Nesse trabalho as teses da Faculdade de Medicina do Rio de Janeiro e da Bahia foram usados como fontes, sendo selecionadas aquelas que possuíam os termos "collegios", "escholar", "hygiene escholar", "educação physica" e "gymnastica”.

Esses autores chegaram à conclusão de que a relevância da ginástica era "secundária" no "projeto higienista" e que a "mentalidade higienista" colaborou para a lenta difusão dos exercícios físicos no século XIX. Esses autores apontam também que, no final do século XIX, a ginástica tornou-se mais importante na defesa do "projeto higienista" dos médicos.

Para os autores, a ginástica era "secundária" porque era uma das partes da proposta de higiene defendida pelos médicos. A ginástica não ocupava um lugar central dentro da educação física. Na proposta de educação física, a ginástica dividia espaço com uma gama ampla de aspectos.

Acredito que seja possível relativizar papel "secundário" da ginástica a partir de outra perspectiva que considere que a ginástica estava envolvida num amplo projeto de reforma da sociedade pela higiene defendida pelos médicos. Dentro desse projeto a ginástica dividia espaço com outras propostas, também importantes, que deveriam agir em conjunto na higienização da população. Esse projeto acabava refletindo no que os médicos chamavam de educação física. Olhando dessa forma a ginástica não era secundária, mas parte de um projeto mais amplo. Esse olhar é possível se não buscarmos entender a educação física como algo necessariamente ligado ao exercício físico e sim tentando entende-la dentro do que os médicos compreendiam como educação física.

Acredito que esse olhar sobre a documentação poderia dar outra perspectiva sobre o que os médicos concebiam por educação física, sem a necessidade da utilização de um conceito como a "educação do corpo" como o empregado por Soares (2006). O próprio termo educação física, por sua abrangência, oferece eficácia heurística. Porque a história nasce no presente, é imprescindível que ela seja necessária agora (LE GOFF e NORA, 1974, p. 127), além de atentar para que as categorias criadas no presente não sobreponham ou eliminem o fenômeno histórico que se quer pesquisar. Em nenhum momento a "educação do corpo" foi tratada nas fontes, mas a "educação física" sim.

As perguntas que nascem no presente devem ser constantemente modificadas a partir da leitura das fontes. Fazer uma História da Educação Física nos anos finais do século XIX não significa negar a ginástica, ou outras formas de exercícios físicos, esses objetos são de grande importância para o entendimento da educação física. Entretanto fazer a História da Educação Física no século XIX é também estar atendo aos outros elementos que a envolviam. Defendi neste artigo a possibilidade de pensar a educação física para além de práticas corporais, sem negá-las, a possibilidade pensar a educação física como uma expressão de época nos estudos históricos da Educação Física. Possibilidade que só pode ser aberta 
a partir da empiria no trato da documentação.

\section{Referências}

CASTELLANI FILHO, Lino. Educação Física no Brasil: a história que não se conta. Campinas, SP: Papirus, 1988.

COSTA, Luciana Henrique da; SANTOS, Marysol de Souza.; GÓIS JUNIOR, Edivaldo. O discurso médico e a Educação Física nas escolas (Brasil, século XIX). Revista Brasileira de Educação Física e Esporte, v. 28, p. 273-282, 2014.

CUNHA JÚNIOR, Carlos Fernando Ferreira da. A produção teórica brasileira sobre educação physica/gymnastica publicada no século XIX: autores, mercado e questões de gênero. In: FERREIRA NETO, Amarílio. (org.). Pesquisa Histórica na Educação Física, v. 3. 1ed. Aracruz, ES: FACHA, 1998.

DUBY, Georges. A história contínua. Rio de Janeiro: Zahar Ed. UFRJ, 1993.

FERREIRA NETO, Amarílio. Apresentação. In: FERREIRA NETO, Amarílio. (org.). Pesquisa histórica na educação física. Aracruz, ES: Faculdade de Ciências Humanas de Aracruz, 1998

. O contexto de produção de Educação Física no Brasil: a história que não se conta. In: FERREIRA NETO, A.(org.). Pesquisa histórica na educação física brasileira. Vitória ES: UFES, 1996.

KNAUSS, Paulo. Usos do passado, arquivos e universidades. Cadernos de Pesquisa do CDHIS (UFU), $v$. 40, p. 9-15, 2009.

GHIRALDELLI JUNIOR, Paulo. A volta ao que parece simples. Movimento, v. 2, n. 2, p. XV-XVII, 1995.

GÓIS JUNIOR, Edivaldo. Ginástica, higiene e eugenia no projeto de nação brasileira: Rio de Janeiro, século XIX e início do século XX. Movimento, v. 19, p. 139-159, 2013.

LE GOFF, Jacques; NORA, Pierre. Apresentação a Faire de lihistoire [1974]. In: NOVAIS, Fernando A.; FORASTIERI, Rogerio. (orgs.). Nova história em perspectiva, volume 1. São Paulo: Cosac Naify, 2011.

MELO, Victor Andrade de. A educação física nas escolas brasileiras do século XIX: esporte ou ginástica? In: FERREIRA NETO, Amarílio. (org.). Pesquisa histórica na educação física v.3. Aracruz: Ed. Faculdade de Ciências Humanas de Aracruz, 1998.

. História da História da Educação Física no Brasil: perspectivas e propostas para a década de 90. Revista Brasileira de Ciências do Esporte. Santa Maria, v. 16, n.2, p. 134-143, 1995.

. Reflexão sobre a História da Educação Física no Brasil: uma abordagem historiográfica. Movimento, n. 4, v. p. 1, 41-48, 1996.

São Paulo: IBRASA, 1999.

. História da Educação Física e do Esporte no Brasil: panorama e perspectiva. 
MELO, Victor Andrade de; GOELLNER, Silvana Vilodre; GENOVEZ, Patricia Falco; PAIVA, Fernanda Simone de Lopes; CUNHA JUNIOR, Carlos Fernando Ferreira da. Projeto bibliografias: descortinando fontes para a História da Educação Física e do Esporte no Brasil. In: FERREIRA NETO, Amarílio. (org.). Pesquisa histórica na educação física. Aracruz, ES: Faculdade de Ciências Humanas de Aracruz, 1998.

SOARES, Carmen Lúcia. Do Corpo, da Educação Física e das muitas Histórias. Movimento, Porto Alegre, v. 9, n.3, p.125-147, 2003 a.

. Educação física: raízes européias e Brasil. 3. Ed. Campinas, SP: Autores Associa-

dos, 2004 .

- Imagens da Educação do Corpo: estudo a partir da ginástica francesa no século XIX. 1996, 198f. Tese (Doutorado em Educação) Universidade Estadual de Campinas, Campinas, 1996.

- Imagens da Educação no Corpo: estudo a partir da ginástica francesa no século XIX. Campinas: Autores Associados, 1998.

. Imagens do Corpo “educado": Um olhar sobre a ginástica no século XIX. In: FERREIRA NETO, Amarílio. (org.). Pesquisa história na educação física, vol. 2. Vitória: UFES, 1997.

. Prefácio. In: OLIVEIRA, Marcus Aurelio Taborda. (org.) Educação do corpo na escola brasileira. Campinas, SP: Autores Associados, 2006.

OLIVEIRA, Marcus Aurelio Taborda de. (org.) Educação do corpo na escola brasileira. Campinas, SP: Autores Associados, 2006.

PAGNI, Pedro Ângelo. A prescrição dos exercícios físicos e do esporte no Brasil (1850-1920): cuidados com o corpo, educação física e formação moral. In: FERREIRA NETO, Amarílio. (org.). Pesquisa histórica na educação física, vol. 2. Vitória: UFES, 1997.

POMPEIA, Raul. O Ateneu. São Paulo: Ciranda Cultural, 2009.

SCHUELER, Alessandra Martinez Frota de; MAGALDI, Ana Maria. Educação escolar na Primeira República: memória, história e perspectiva de pesquisa. Tempo, v. 26, p. 32-55, 2009.

THOMPSON, Edward Palmer. A História vista a partir de baixo. In: SERGIO SILVA, Antonio Luigi (orgs.). As peculiaridades dos ingleses e outros artigos: E. P. Thompson. Textos Didáticos, n. 10, v. 2, fevereiro de 1998, Campinas, IFCH/Unicamp, 1998a.

. Sobre classe e falsa consciência. In: SERGIO SILVA, Antonio Luigi (org.). As peculiaridades dos ingleses e outros artigos: E. P. Thompson. Textos Didáticos, n. 10, v. 2, fevereiro de 1998, Campinas, IFCH/Unicamp, 1998 b.

VAGO, Tarcísio Mauro. A escolarização da gymnastica nas escolas normais de Minas Gerais. In: FERREIRA NETO, Amarílio. (org.). Pesquisa histórica na educação física, v.2. Vitória: UFES, 1997. 